\title{
¿Quién obtiene préstamos para acumular activos? Clase, género y endeudamiento en el mercado crediticio del Ecuador ${ }^{1}$
}

\author{
Carmen Diana Deere y Zachary B. Catanzarite
}

\section{Resumen}

En el presente artículo se examinan los planteos de que la desigual distribución de la riqueza explica la segmentación del mercado crediticio y que el sistema financiero puede reproducir la desigualdad económica. En particular, examinamos de qué modo las fuentes del crédito y la finalidad de los préstamos pueden contribuir a perpetuar la desigualdad. En el Ecuador, las personas pobres en activos tienen más probabilidades que las personas ricas en activos de obtener préstamos en el sector informal y de utilizar estos préstamos para pagar sus gastos en vez de invertirlos en activos. También es más probable que la relación entre la deuda y la riqueza neta de las primeras sea más elevada. Investigamos asimismo las correlaciones en la obtención de préstamos por hombres y mujeres para adquirir activos, y mostramos que tener una cuenta de ahorros formal es el principal factor asociado con tener deudas destinadas a activos en ambos sexos.

Palabras clave

Servicios financieros, género, incorporación de la perspectiva de género, clases sociales, préstamos, deuda, instituciones financieras, sector informal, indicadores económicos, Ecuador

Clasificación JEL

N26, D31, J16

Autores

Carmen Diana Deere es Profesora Emérita Distinguida de Estudios Latinoamericanos y Economía Agrícola de la Universidad de Florida (Estados Unidos) y Profesora-Investigadora Emérita Honoraria de la Facultad Latinoamericana de Ciencias Sociales (FLACSO)-Ecuador. deere@ufl.edu

Zachary B. Catanzarite es Investigador Asociado del Centro de Estudios de América Latina de la Universidad de Florida (Estados Unidos). zcatanz@ufl.edu

\footnotetext{
Una versión anterior de este artículo se presentó en el Congreso Internacional de la Asociación de Estudios Latinoamericanos, que se llevó a cabo en San Juan del 27 al 30 de mayo de 2015, y en el III Congreso Latinoamericano y del Caribe de Ciencias Sociales, Facultad Latinoamericana de Ciencias Sociales (FLACSO), que tuvo lugar en Quito del 26 al 28 de agosto de 2015. El artículo está basado en un trabajo que se hizo como parte del proyecto Gender Asset Gap y el análisis comparativo de la deuda de los hogares y las personas en el Ecuador, Ghana y la India con financiación de la Entidad de las Naciones Unidas para la Igualdad de Género y el Empoderamiento de las Mujeres (ONU-Mujeres). Los autores agradecen los aportes que recibieron de Caren Grown, Abena Oduro, Hema Swaminatham y Cheryl Doss, que dieron forma a muchas de las ideas que aquí figuran. También agradecen los comentarios de Adolfo Figueroa y Priscila Hermida Bermeo, que mejoraron el análisis.
} 


\section{Introducción}

En décadas recientes, uno de los principales objetivos de las políticas de desarrollo de América Latina ha sido la inclusión financiera: extender el acceso al crédito y a otros servicios financieros a quienes generalmente han estado excluidos de los mercados crediticios formales. Si bien no hay dudas de que el rápido aumento de la cantidad de instituciones de microfinanzas en toda la región ha ampliado el acceso al crédito, preocupa la posibilidad de que los pobres estén subrepresentados en esa expansión, como se menciona en los reiterados llamamientos a profundizar más el alcance de este (Peck y Miller, 2006; De la Torre, Ize y Schmukler, 2011). Al mismo tiempo, debido a las recientes crisis de microcréditos en los países en desarrollo, preocupa que el crecimiento de las microfinanzas haya conducido a un sobreendeudamiento, en particular entre los pobres (Schicks, 2013a; Bastiaensen y otros, 2013).

Figueroa (2011) sostiene que, mientras en América Latina siga habiendo una elevada desigualdad en materia de riqueza, la región seguirá teniendo una estructura financiera compuesta por tres sectores en que los pobres pagan más que los ricos para acceder al crédito. Los tres sectores que integran esa estructura financiera son los siguientes: i) los bancos privados; ii) las entidades formales no bancarias, como las cooperativas de ahorro y crédito y las mutuales crediticias, y iii) el sector informal, integrado principalmente por prestamistas, pero también por familiares y amigos. Figueroa (2011) también demuestra que la desigualdad de la riqueza predice la segmentación del mercado, ya que los ricos recurren a los bancos formales, los menos ricos a las entidades formales no bancarias y los pobres al sector informal. Un rasgo distintivo de esta estructura financiera es que el crédito que otorgan las entidades no bancarias es más oneroso que el que otorgan los bancos formales y que, del mismo modo, el que otorga el sector informal es más oneroso que el de las entidades no bancarias². Esto se debe sobre todo al papel que desempeña la garantía - que siempre es un requisito de los bancos privados - como reductora del riesgo, así como a las economías de escala que se generan en relación con los costos de transacción de los préstamos grandes. En síntesis, aquellos que cuentan con activos suficientes (los ricos) pueden ofrecer garantías y obtener mejores condiciones de crédito en el sector bancario privado, mientras que el exceso de demanda proveniente de quienes no cuentan con activos suficientes se canaliza hacia los segmentos más onerosos.

En el presente artículo desarrollamos este argumento en el caso del Ecuador y lo llevamos un paso más allá al demostrar cómo la finalidad de los préstamos puede exacerbar aún más la desigualdad económica. Si los ricos y los pobres obtienen préstamos con diferentes fines, los primeros para acumular activos y los segundos más que nada para pagar los gastos corrientes, entonces expandir el acceso al crédito a través de las microfinanzas, por ejemplo, podría mitigar la pobreza en el corto plazo y al mismo tiempo reproducir la concentración de la riqueza entre quienes son ricos en activos. También es posible que el diferente destino que se les da a los préstamos, combinado con la segmentación del mercado crediticio, permita explicar por qué la relación entre la deuda y la riqueza neta de los pobres podría ser superior a la de los ricos, y por qué los primeros podrían tener más probabilidades de caer en una trampa de endeudamiento.

Investigamos la relación entre la riqueza neta de los hogares, las fuentes de crédito y la finalidad de los préstamos. Para ello, empleamos una base única de datos acerca de la riqueza de los hogares en el Ecuador. Esta base de datos nos permite analizar los préstamos que los hogares y las personas obtienen de todas las fuentes y para todas las finalidades. En este análisis, empleamos los quintiles de riqueza neta del hogar como indicador indirecto de la posición de clase, y distinguimos entre los ricos en activos (los que tienen activos suficientes como para ofrecer garantía por los

\footnotetext{
2 Véase Banerjee y Duflo (2010) acerca de algunos de los hechos estilizados relativos a los mercados de crédito de los países en desarrollo, como las diferencias que hay entre las tasas de interés que se cobran en el sector formal y el sector informal.
} 
préstamos) y los pobres en activos (aquellos que no los tienen) ${ }^{3}$. En nuestra encuesta también se recopiló información acerca de cuál de los integrantes del hogar era responsable de reembolsar los préstamos. De este modo, combinamos un análisis de clase con un análisis de género. Analizamos las correlaciones de la obtención de préstamos por hombres y mujeres para adquirir activos, así como la relación entre la deuda y la riqueza neta a nivel individual y por género, temas que no se han examinado en mucha profundidad.

La mayoría de los estudios cuantitativos suelen centrarse solo en los hogares que tienen empresas (o emprendedores individuales) o en hogares que participan en actividades agrícolas. En esos estudios se examina el acceso al crédito y el uso que se le da solo en relación con esas actividades específicas, es decir, lo que a menudo se denomina "crédito productivo". En nuestro enfoque, que se centra en las finanzas del hogar, se toma en cuenta que los hogares con frecuencia participan en múltiples actividades que generan ingresos y pueden obtener préstamos de diversas fuentes con múltiples fines. Además, se considera el hecho de que los préstamos son fungibles: pueden obtenerse con un fin pero utilizarse de diversas maneras (Collins, 2008).

Definimos los préstamos destinados a activos como préstamos que se obtienen con la finalidad de adquirir o mejorar un activo físico. Nuestra definición de los préstamos destinados a activos es más amplia que la noción habitual de crédito "productivo", porque nos interesa la relación entre la distribución de la riqueza, el acceso al crédito y el endeudamiento. Es convencional definir la riqueza como la suma del valor de los activos físicos (en particular, la vivienda y los bienes de consumo duraderos) y los activos financieros (Davies, 2008). En un sistema financiero dividido en tres sectores, la mayoría de los activos físicos y financieros podrían servir como garantía de los préstamos. Por ejemplo, si bien sería muy difícil que los bienes de consumo duraderos, con la posible excepción de los vehículos, bastaran para ser utilizados como garantía de un préstamo en un banco privado, es posible que un televisor, una cocina o un refrigerador se acepten como garantía en una institución no bancaria y en el sector informal, dado que estos se pueden vender o prendar para cumplir con el pago de la deuda (Vogelgesang, 2003) ${ }^{4}$. Además, aunque una cocina o un refrigerador que se haya comprado en cuotas no se utilice en relación con una empresa en el momento, puede convertirse en el medio para que una mujer lleve a cabo una actividad laboral independiente (vender comida elaborada o bebidas frías), si surge la necesidad, del mismo modo que tener un vehículo puede convertirse en un posible medio para que un hombre genere ingresos ofreciendo servicios de transporte.

Los préstamos destinados a gastos comprenden aquellos que se obtienen para hacer frente a los gastos diarios, como alimentos, pago de servicios públicos, transporte o vestimenta; gastos de educación, salud y celebraciones; gastos de migración y reembolso de préstamos anteriores. Por consiguiente, también nos apartamos del análisis convencional al considerar que la educación y la salud son gastos y no inversiones en capital humano, dado que los beneficios financieros que generan pueden presentarse en el largo y no en el corto plazo, y porque no siempre el hogar que asume la deuda es el que ha de gozar de esos beneficios.

Demostramos que, en el Ecuador, los ricos en activos tienen más probabilidades de obtener préstamos de fuentes formales y de hacerlo con el fin de acumular activos. Por el contrario, los pobres en activos recurren más a las fuentes informales y tienen más probabilidades de pedir préstamos para hacer frente a los gastos del hogar. No sorprende que la relación entre la deuda y la riqueza neta de los pobres sea superior a la de los ricos. La amplia mayoría de los préstamos que se obtienen

3 Es probable que los quintiles de riqueza neta que empleamos se correspondan con la estructura analítica de clases que propusieron Portes y Hoffman (2003) para América Latina, donde el quintil más rico está integrado por capitalistas, gerentes de grandes y medianas empresas, y profesionales asalariados y de las instituciones públicas, mientras que el quintil más pobre está integrado por trabajadores del sector informal.

4 Véase CAF (2011, cuadro 4.7) para obtener una descomposición detallada de los tipos de garantías que aceptan una serie de fuentes de crédito formales e informales, en un estudio de microempresarios de Colombia. 
en el Ecuador provienen de fuentes formales; no obstante, cuando se comparan los préstamos que se solicitan en pareja y los que se solicitan de forma individual por hombres o por mujeres, hay más probabilidades de que estos últimos se obtengan de fuentes informales, en particular en el caso de las mujeres. Del mismo modo, aunque la gran mayoría de los préstamos se obtienen con el fin de acumular activos, es más probable que aquellos por los que las mujeres son responsables de forma individual se destinen a pagar gastos.

Dado que nuestro interés principal es la relación entre el uso del crédito y la desigualdad económica, hacemos un análisis de regresión logística para investigar los factores que se correlacionan con los préstamos destinados a la adquisición de activos. Nuestros resultados sugieren que, sin importar el género, el principal factor asociado con la tenencia de deudas destinadas a activos es tener una cuenta de ahorros formal. Por otra parte, se observa una gran diferencia entre los géneros en cuanto a la importancia de percibir ingresos propios: esa variable está muy asociada solo con las mujeres cuando se trata de solicitar un préstamo para acumular activos. En términos generales, la relación más preocupante entre la deuda y la riqueza neta la presentan quienes pertenecen al quintil de menor riqueza, en particular los hombres más pobres, pero es posible que las mujeres más pobres sean las que tienen el grado más elevado de endeudamiento excesivo, como lo indica la necesidad de reciclar los préstamos. En su conjunto, el análisis respalda lo que plantea Figueroa (2011): en el sistema financiero compuesto por tres sectores, la riqueza engendra riqueza.

A continuación de la presente Introducción, el artículo se organiza de la siguiente manera. En la sección II se describe el sistema financiero del Ecuador y se hace una síntesis de los estudios disponibles acerca del uso del crédito en los hogares y la desigualdad económica. En la sección III se presenta la metodología de la encuesta nacional sobre los activos de los hogares que se llevó a cabo en el Ecuador en 2010, y luego se investigan las fuentes y la finalidad de los préstamos, por clase y género. En la sección IV se exponen los análisis de las regresiones logísticas que se emplearon para analizar los factores asociados con el hecho de que los particulares obtengan préstamos para acumular activos. En la sección $\vee$ se examina el endeudamiento de los hombres y las mujeres por clase y, en la sección VI, se presentan las conclusiones.

\section{El contexto ecuatoriano}

El sistema financiero del Ecuador se ha recuperado de la crisis que tuvo lugar en 1999 y 2000, que condujo a la adopción del dólar de los Estados Unidos como moneda oficial del país. Esa crisis se caracterizó por la quiebra de 22 bancos comerciales, que tenían aproximadamente el $60 \%$ de los activos del sistema financiero privado, y fue la culminación de casi diez años de inestabilidad económica. La mayoría de los analistas atribuyen esa inestabilidad a varios factores combinados: la desregularización y liberalización financiera, la deuda externa excesiva, la marcada fluctuación de los precios del petróleo (el principal producto de exportación del país) y la inestabilidad política (Da Ros, 2003; Jácome, 2007).

En la década siguiente, se emprendió la tarea de restablecer la confianza de las personas mediante la reconstrucción del sistema bancario público, que se había desmantelado, y la regulación estatal del sistema bancario privado. En 2006, el crédito de los bancos privados ascendía al 22\% del producto interno bruto (PIB), lo que colocaba al Ecuador por debajo del promedio latinoamericano, pero por encima de otras economías mucho más grandes, como las del Perú y México (Fanelli, 2011, cuadro 10.1). Hacia 2010, esa proporción se había incrementado al $28 \%{ }^{5}$.

\footnotetext{
5 Véase Banco Mundial [en línea] http://econ.worldbank.org/WBSITE/EXTERNAL/EXTDEC/EXTRESEARCH/0,,contentMDK:20 696167 pagePK:64214825 piPK:64214943 theSitePK:469382,00.html, para la proporción del PIB que representa el crédito privado de los bancos de depósito y otras instituciones financieras.
} 
En la actualidad, hay dos instituciones que regulan el sistema financiero privado formal: la Superintendencia de Bancos y Seguros (SBS) del Ecuador y la Superintendencia de Economía Popular y Solidaria (SEPS). La SBS regula todos los bancos comerciales privados, que en 2013 eran 24, frente a los 96 que había antes de la crisis financiera. Desde 2013, la SEPS regula todas las formas de asociaciones financieras cooperativas. Antes de ese año, la SBS regía las cooperativas de ahorro y crédito de mayor tamaño (las que tenían activos por más de 1 millón de dólares y depósitos por más de 200.000), y el Ministerio de Inclusión Económica y Social regía las que se encontraban por debajo de ese umbral.

Si bien muchas de las cooperativas de ahorro y crédito se crearon en la década de 1960, su número creció rápidamente en todo el país después del colapso del sector bancario. En 2002, un censo de las cooperativas de ahorro y crédito y de los bancos y fondos comunales reveló que, en ese momento, había 26 cooperativas reguladas que respondían a la SBS y 350 instituciones no reguladas que dependían del Ministerio. Estas últimas tenían más de medio millón de socios (Jácome y Cordovéz, 2004). Hacia junio de 2013, había 773 cooperativas de ahorro y crédito que dependían de la SEPS. Como se observa en el cuadro 1, estas se clasifican por tamaño, y las cooperativas más grandes (segmento 4) son las que antes dependían de la SBS ${ }^{6}$.

\section{Cuadro 1}

Ecuador: distribución de los préstamos entre los bancos privados y las cooperativas de ahorro y crédito de diferentes tamaños, según la finalidad, junio de 2013

(En porcentajes)

\begin{tabular}{|c|c|c|c|c|c|c|}
\hline Institución & Cantidad & Comerciales & De consumo & De vivienda & Microempresariales & Total $^{\mathrm{a}}$ \\
\hline Bancos privados & 24 & 48 & 35,7 & 8,5 & 7,8 & $\begin{array}{c}100 \% \\
\text { (16 } 300 \text { millones de dólares) }\end{array}$ \\
\hline \multicolumn{7}{|l|}{ Cooperativas $^{\mathrm{b}}$} \\
\hline Segmento 4 & 40 & 4 & 51,2 & 7,3 & 37,5 & $\begin{array}{c}100 \% \\
\text { (3 } 300 \text { millones de dólares) }\end{array}$ \\
\hline Segmento 3 & 78 & 0,9 & 49,5 & 8,8 & 40,8 & $\begin{array}{c}100 \% \\
\text { (1 } 200 \text { millones de dólares) }\end{array}$ \\
\hline Segmento 2 & 296 & 4,9 & 39 & 2 & 54 & $\begin{array}{c}100 \% \\
\text { (500 millones de dólares) }\end{array}$ \\
\hline Segmento 1 & 359 & 9,3 & 37,7 & 1,5 & 52,4 & $\begin{array}{c}100 \% \\
\text { (100 millones de dólares) }\end{array}$ \\
\hline Subtotal & 773 & 3,4 & 49,5 & 7,1 & 40 & $\begin{array}{c}100 \% \\
\text { (5 } 000 \text { millones de dólares) }\end{array}$ \\
\hline
\end{tabular}

Fuente: Elaboración propia, sobre la base de la Superintendencia de Bancos y Seguros (SBS), Boletín de Series Bancos Privados, 2013 [en línea] http://www.sbs.gob.ec; y Superintendencia de Economía Popular y Solidaria (SEPS), Boletín Financiero - Sector Financiero Popular y Solidario al 30 de junio de 2013, 2013 [en línea] http://www.seps. gob.ec.

a El total también incluye una quinta categoría, préstamos para educación, que representa menos del 1\% de la cartera total.

b Los segmentos se refieren a la estratificación de las cooperativas de ahorro y crédito por tamaño, definido según el valor del total de sus activos, la cantidad de socios y la amplitud de la cobertura geográfica, donde el segmento 4 representa las cooperativas más grandes.

Las carteras de préstamos de los bancos privados y las cooperativas de ahorro y crédito tienen una composición muy diferente, como también se observa en el cuadro 1. Las cooperativas de ahorro y crédito atienden a las microempresas y a los hogares, mientras que los bancos privados otorgan préstamos más que nada para fines comerciales. En términos relativos, los préstamos de consumo

6 En las cooperativas de ahorro y crédito (principalmente en los segmentos 1 y 2) se incluyen las instituciones conocidas como bancos o fondos comunales (que con frecuencia solo tienen de 25 a 30 socios en promedio), así como otros grupos locales de microfinanzas que crean las organizaciones no gubernamentales. Además del tamaño y la cobertura geográfica, una de las principales distinciones entre estas formas diversas es que las cooperativas de ahorro y crédito pueden aceptar depósitos de personas que no son socias, mientras que las otras formas solo pueden tener los ahorros de sus socios (SEPS, 2014). 
(según su definición tradicional) representan una proporción relativamente grande de las carteras de préstamos tanto de los bancos privados como del sector de las cooperativas de ahorro y crédito: el $36 \%$ y el $50 \%$, respectivamente.

Otra característica del sistema financiero ecuatoriano es que el banco central establece las tasas de interés máximas que se pueden cobrar en los préstamos del sector formal. Como se observa en el cuadro 2, las tasas varían según el tipo de institución y la finalidad del préstamo. Como predice el modelo de Figueroa (2011), las tasas de interés más bajas son la que ofrecen los bancos privados a los clientes empresariales, y las tasas más altas son las que ofrecen las instituciones microfinancieras en los microcréditos. En 2010, la tasa más alta de los préstamos a las sociedades ascendía al 9,3\% al año, mientras que las tasas de los microcréditos iban del 25,5\% al 30,5\%, según el tamaño del préstamo. En el trabajo de campo cualitativo que llevamos a cabo en el Ecuador en 2009-2010, se decía que los prestamistas cobraban entre el $10 \%$ y el $20 \%$ al mes ${ }^{7}$.

Cuadro 2

Ecuador: tasas de interés máximas, diciembre de 2010

(En porcentajes)

\begin{tabular}{|c|c|}
\hline Finalidad & Tasa de interés ${ }^{a}$ \\
\hline \multicolumn{2}{|l|}{ Comercial } \\
\hline Corporativo ${ }^{\mathrm{b}}$ & 9,3 \\
\hline Pequeñas y medianas empresas ${ }^{C}$ & 11,8 \\
\hline Vivienda & 11,3 \\
\hline Bienes de consumo & 16,3 \\
\hline \multicolumn{2}{|l|}{ Microcrédito ${ }^{d}$} \\
\hline Préstamos de 8500 dólares y más & 25,5 \\
\hline Préstamos de entre 600 y 8500 dólares & 27,5 \\
\hline Préstamos inferiores a 600 dólares & 30,5 \\
\hline
\end{tabular}

Fuente: Elaboración propia, sobre la base de Banco Central del Ecuador (BCE), Evolución del volumen de crédito y tasas de interés: análisis del sistema de finanzas públicas y privado del Ecuador, Quito, 2013 [en línea] http://contenido.bce. fin.ec/documentos/Estadisticas/SectorMonFin/BoletinTasasInteres/ect201312.pdf.

a Hasta 2014 se mantuvieron las mismas tasas máximas de interés.

b Empresas con ventas anuales superiores a 5 millones de dólares.

c Empresas con ventas anuales de entre 100.000 dólares y 5 millones de dólares.

d Empresas con ventas anuales inferiores a 100.000 dólares.

Uno de los principales factores que ha impulsado el movimiento microfinanciero en el Ecuador desde 2000 ha sido la Red Financiera Rural (RFR), que reúne a los bancos privados que trabajan en este subsector, las cooperativas de ahorro y crédito, y las organizaciones no gubernamentales que cuentan con programas de microfinanzas. Estas instituciones, cuya misión es la inclusión financiera, trabajan tanto en las zonas rurales como con los pobres de las zonas urbanas. Su cartera de préstamos combinada ha aumentado de forma constante: creció a un ritmo de aproximadamente el $10 \%$ anual durante la década de 2000 (Readout, 2011, pág. 30) y se duplicó con creces entre 2010 y 2013 (RFR, 2013).

En el Ecuador solo se han llevado a cabo unas pocas encuestas a gran escala en las que se examina el modo en que los hogares, a diferencia de las empresas, utilizan el crédito, sin importar la fuente. Estas encuestas señalan una recuperación de la confianza en el sistema financiero privado y

\footnotetext{
7 Grupos de discusión en las provincias de Pichincha y Manabí. Véase asimismo Floro y Messier (2006, pág. 239) para obtener información acerca de las altas tasas de interés que cobraban los prestamistas en Quito y Guayaquil.
} 
una creciente inclusión financiera. En una encuesta de hogares representativa de las tres ciudades más grandes (Quito, Guayaquil y Cuenca) en 2003, se halló que solo el 12,5\% de los hogares urbanos había obtenido un préstamo en los 12 meses anteriores (Jácome, 2005). Un análisis de la Encuesta de Condiciones de Vida del Ecuador de 2006, que es representativa a nivel nacional, mostró que el $51,5 \%$ de los hogares había obtenido un préstamo (sin importar el fin) el año anterior. En la encuesta representativa a nivel nacional sobre los activos de los hogares, que llevamos a cabo en 2010 y se describe a continuación, hallamos que el $46 \%$ de los hogares tiene un préstamo pendiente. Si bien el alcance y el método de estas encuestas son diferentes, ellas respaldan la conclusión de que el sistema financiero se recuperó y expandió en el transcurso de la década de 2000.

Mideros (2010) utiliza los módulos de crédito de la Encuesta de Condiciones de Vida de 2006 y analiza el papel que desempeña la desigualdad del ingreso en el uso de los diferentes tipos de crédito en el Ecuador. Halla que los préstamos de consumo en efectivo tienen una incidencia mucho menor entre los hogares de los dos quintiles más pobres (22\% y $26 \%$, respectivamente) que entre los que corresponden a los dos quintiles más ricos (31\% en cada uno). Según lo que se indicó en esa encuesta, los préstamos a plazos para adquirir activos, productos y servicios son la forma de crédito que se usa con mayor frecuencia. En lo que respecta a ese tipo de crédito, Mideros encuentra una diferenciación todavía mayor, ya que el $24 \%$ de los hogares del quintil I de riqueza neta tiene ese tipo de préstamo, en comparación con el $40 \%$ del quintil $V$ (Mideros, 2010, gráfico 17). En cuanto al crédito para negocio, en el quintil más pobre hay menos hogares que tienen negocios (31\%) y, entre ellos, solo el 9\% tiene un préstamo de ese tipo. En cambio, entre los hogares del quintil superior aproximadamente el 57\% tiene un negocio, y de ellos el 20\% tiene un préstamo destinado a ese fin (Mideros, 2010, gráfico 18). En términos generales, sus resultados sugieren una diferenciación considerable en el uso del crédito según el quintil de ingresos al que pertenezca el hogar. Planteamos que, si se toma en cuenta la distribución de la riqueza en lugar de los ingresos, se puede obtener una medida más sólida del papel que desempeña la desigualdad económica en el uso del crédito.

\section{La encuesta sobre los activos de los hogares del Ecuador}

En 2010, FLACSO-Ecuador y la Universidad de Florida llevaron a cabo la encuesta sobre los activos de los hogares del Ecuador, que se conoce con el nombre de Encuesta Activos FLACSO-Florida (EAFF), como parte de un estudio comparativo internacional. A los efectos de la encuesta, se hizo un muestreo estratificado de dos etapas, diseñado para ser representativo de las regiones de la costa y sierra del Ecuador, y que dio como resultado una muestra de 2.892 hogares. El objetivo principal fue medir la propiedad de los activos a nivel de los hogares y a nivel individual. Con ese fin, se emplearon dos instrumentos: un inventario de los activos físicos del hogar y un cuestionario individual. La encuesta se dirigió a los jefes del hogar, y el inventario de los activos lo completó la pareja principal en conjunto, siempre que esto fue posible. En relación con cada activo físico - residencia principal, terrenos agrícolas, otros bienes raíces, animales, equipamiento e instalaciones agropecuarias, negocios y bienes de consumo duraderos -, se obtuvo una lista completa de los propietarios, además de información acerca de si había alguna deuda pendiente asociada al activo. Luego, cada uno de los encuestados por separado respondió el cuestionario individual, que se centró en información complementaria sobre la propiedad de los activos, en particular los ahorros individuales, la deuda que se tenía en el momento, los préstamos otorgados a terceros y otras consideraciones, como la toma de decisiones en el hogar.

En el módulo sobre la deuda individual, se solicitó información acerca de todos los préstamos que el encuestado había obtenido y aún no había terminado de pagar. Por consiguiente, es posible que 
en los datos esté subestimado el total de los préstamos obtenidos durante un año determinado, ya que se excluyen los de corto plazo que se cancelaron durante los 12 meses anteriores. Esta deficiencia se compensa con el hecho de que la medición de la deuda pendiente, que incluye préstamos adquiridos en los años anteriores, proporciona una visión más completa del endeudamiento individual. Dado que la información acerca de la deuda se recopiló tanto a nivel del hogar como individual, llevó mucho tiempo conciliar los datos. Si bien el método que se utilizó para recoger los datos produjo cierta duplicación y posibles errores de identificación (debido a que, en ocasiones, los esposos y las esposas proporcionaron información contradictoria en relación con los datos de un mismo préstamo), ofreció la ventaja de maximizar la posibilidad de captar información acerca de todas las deudas pendientes. Otra carencia de nuestra encuesta fue el hecho de que no recogimos información acerca de las tasas de interés ni las condiciones de esos préstamos.

Por último, cabe mencionar que los resultados de la encuesta están truncados, dado que no pudimos obtener una muestra representativa de los hogares del grupo socioeconómico más rico, debido sobre todo a que la tasa de rechazo entre este grupo fue del 100\% en Quito. No obstante, el coeficiente de Gini de concentración de la riqueza bruta que estimamos asciende a 0,68, valor que, como es de esperarse, es muy superior a la estimación oficial de este coeficiente para la concentración del ingreso en el año de la encuesta, que era de 0,52 (Deere y Contreras, 2011).

En el análisis que sigue, el valor de los activos individuales y del hogar se estima según su valor de mercado (de acuerdo a las respuestas que dieron los encuestados sobre el valor al que podrían vender cada activo en ese momento, en el estado en que estaba). Se incorpora el diseño de la muestra en todos los resultados, y estos se ponderan utilizando los factores de expansión de la muestra para que las estimaciones sean representativas a nivel nacional.

\section{Fuentes formales e informales de préstamos}

En términos generales, de los 1.791 préstamos pendientes que se declararon en la encuesta, el $70 \%$ se obtuvieron de fuentes formales y el 30\% de fuentes informales. En el gráfico 1 se resume la distribución de los préstamos por quintil y por fuente, y se muestra que la mayoría de los préstamos de los grupos de todos los quintiles provienen de fuentes formales. No obstante, los quintiles más ricos tienen más probabilidades de tener préstamos formales que los quintiles más pobres, y estos últimos tienen más probabilidades de recurrir a fuentes informales que los primeros.

En el cuadro 3 se presenta esta información por quintil de riqueza neta y a nivel de los hogares (se considera si alguna persona del hogar tiene un préstamo pendiente). Si bien es cierto que los hogares difieren en cuanto a si tienen algún préstamo (el 53\% de los hogares del quintil $\bigvee$ frente al $43 \%$ de los del quintil I), la diferencia más grande se encuentra en lo que respecta a la fuente. Entre los hogares del quintil $\mathrm{V}$, el $45 \%$ tiene un préstamo formal y solo el 15\% tiene uno informal. Las cifras correspondientes al quintil I son $29 \%$ (formal) y el $20 \%$ (informal). 


\section{Gráfico 1}

Ecuador: proporción de préstamos formales e informales por quintil de riqueza neta del hogar, 2010

(En porcentajes)

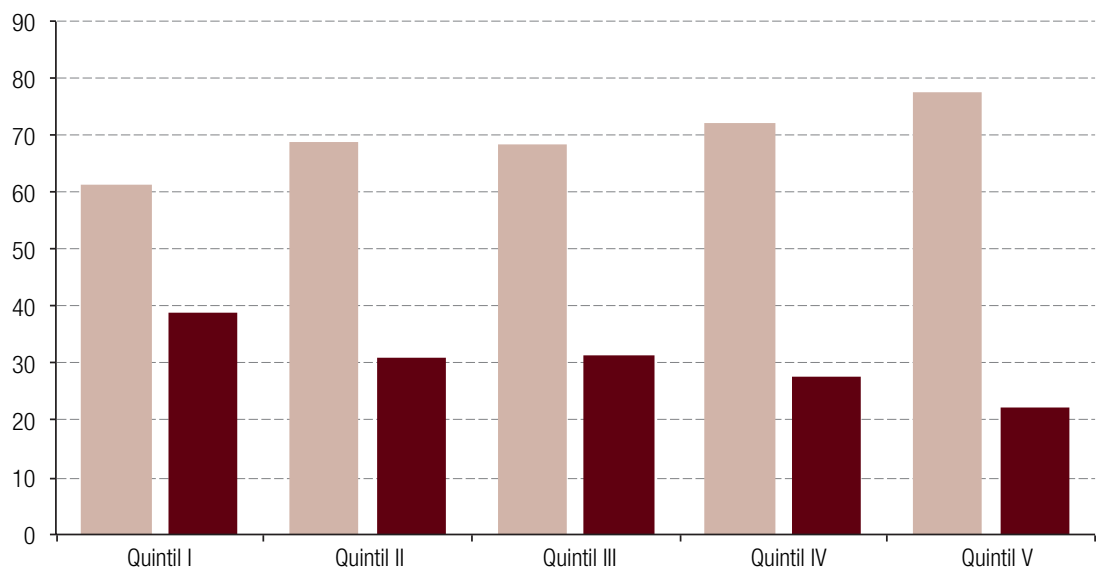

Subtotal formal Subtotal informal

Fuente: Elaboración propia, sobre la base de Encuesta Activos FLACSO-Florida (EAFF), 2010 [en línea] http://www. flacsoandes.edu.ec/pagina/60759-documentos-de-encuesta-activos-flacso-florida.

\section{Cuadro 3}

Ecuador: incidencia de los préstamos formales e informales de los hogares por quintil de riqueza neta y fuente de crédito, 2010

(En porcentajes)

\begin{tabular}{|c|c|c|c|c|c|c|}
\hline \multirow{2}{*}{ Fuente } & \multicolumn{5}{|c|}{ Quintil } & \multirow{2}{*}{ Total de hogares } \\
\hline & 1 & $\|$ & III & IV & V & \\
\hline Banco estatal & 2,3 & 3,9 & 6,5 & 4,8 & 11,4 & 5,8 \\
\hline Banco privado & 4,9 & 6,5 & 6,9 & 9,5 & 16,2 & 8,8 \\
\hline Cooperativa o mutual crediticia & 6,2 & 4,2 & 7,5 & 14,6 & 11,7 & 8,9 \\
\hline $\begin{array}{l}\text { Otra institución privada u organizaciones } \\
\text { no gubernamentales }\end{array}$ & 1,0 & 2,5 & 3,3 & 1,9 & 2,4 & 2,2 \\
\hline Comercio o tienda & 16,2 & 18,2 & 14,6 & 10,7 & 11,2 & 14,2 \\
\hline Tarjeta de crédito & 0,9 & 2,8 & 1,3 & 1,6 & 2,7 & 1,9 \\
\hline Subtotal formal & 29,0 & 34,4 & 35,4 & 36,7 & 45,0 & 36,1 \\
\hline Grupo informal & 0,5 & 0,7 & 3,4 & 0,5 & 0,2 & 1,1 \\
\hline Prestamista & 2,3 & 3,2 & 3,0 & 1,7 & 1,7 & 2,4 \\
\hline Empleador & 1,3 & 0,2 & 0,7 & 1,2 & 1,5 & 1,0 \\
\hline Amigo & 7,4 & 6,3 & 4,6 & 5,1 & 6,5 & 6,0 \\
\hline Familiar & 9,2 & 7,6 & 5,3 & 7,3 & 5,6 & 7,0 \\
\hline Otro & 0,5 & 0,0 & 0,5 & 0,2 & 0,5 & 0,3 \\
\hline Subtotal informal & 19,9 & 16,8 & 16,7 & 15,7 & 14,9 & 16,8 \\
\hline Total $^{\mathrm{a}}$ & 43,2 & 44,8 & 46,1 & 47,9 & 52,7 & 46,9 \\
\hline$n$ & 575 & 601 & 592 & 540 & 584 & 2892 \\
\hline $\mathrm{N}$ & 668995 & 668593 & 669070 & 668756 & 668419 & 3343832 \\
\hline
\end{tabular}

Fuente: Elaboración propia, sobre la base de Encuesta Activos FLACSO-Florida (EAFF), 2010 [en línea] http://www. flacsoandes.edu.ec/pagina/60759-documentos-de-encuesta-activos-flacso-florida.

a La incidencia total se refiere a todos los hogares que tienen un préstamo, sin importar de qué fuente provenga, por lo que es inferior a la suma de las fuentes formales e informales. 
En el cuadro 3 también se brinda un desglose detallado de las fuentes de los préstamos que se clasifican en formales e informales. En el sector formal, la fuente más frecuente de préstamos en general es el crédito que se obtiene en los comercios o las tiendas (que representa el 14\% de los hogares). Estos suelen ser préstamos a plazos correspondientes a la adquisición anterior de productos o servicios ${ }^{8}$. Este es el tipo de préstamo formal más frecuente al que pueden acceder los hogares de los quintiles I a III, algo que no sorprende dada la rápida expansión que el crédito a plazos otorgado por las grandes tiendas ha tenido en el Ecuador en el transcurso de los últimos diez años. La segunda fuente más frecuente de préstamos en términos generales son los bancos privados y las cooperativas de ahorro y crédito, cada uno de los cuales tiene una incidencia del 9\%. Los préstamos que se obtienen de cada una de esas fuentes son mucho más frecuentes entre los hogares que se encuentran en el $40 \%$ superior de la distribución de la riqueza, en comparación con los que se encuentran en el $40 \%$ inferior. Los préstamos de los bancos estatales se inclinan aún más hacia los hogares situados en la parte superior de la distribución de la riqueza ${ }^{9}$. Solo el $2 \%$ de los hogares tienen microcréditos obtenidos de las organizaciones no gubernamentales $u$ otros otorgadores de préstamos privados (como grupos religiosos), y esos préstamos son un poco menos frecuentes entre los hogares del quintil inferior de riqueza. Por supuesto que el sector microfinanciero no solo abarca los programas de las organizaciones no gubernamentales, puesto que incluye a todas las cooperativas de ahorro y crédito y a siete bancos con servicios microfinancieros, pero, desafortunadamente, no es posible desagregar este sector en nuestros datos.

En lo que respecta a los préstamos del sector informal, la fuente más frecuente en términos generales son los amigos y familiares, característica que se mantiene en los grupos de todos los quintiles, si bien los hogares de los quintiles más pobres tienen una probabilidad levemente mayor de tener préstamos de estas fuentes que los hogares de los quintiles más ricos. Los prestamistas no son una fuente de préstamos que se utilice con mucha frecuencia, ya que solo los mencionaron en el $2 \%$ de los hogares, pero los que se ubican en el $60 \%$ inferior de la distribución recurren más a ellos que los hogares más ricos. Los grupos de crédito informal, como las asociaciones de ahorro y crédito rotativo, son todavía menos comunes. Es probable que la baja incidencia relativa de los prestamistas y los grupos de crédito informal que se obtuvo en nuestra muestra sea un reflejo del aumento de la competencia que impulsó el crecimiento de las instituciones microfinancieras del Ecuador desde comienzos de la década de 2000.

En el cuadro 4 se presenta la distribución de los préstamos según el integrante del hogar que es responsable de reembolsar la deuda. A quienes respondieron el módulo sobre deuda se les pidió en primer lugar que mencionaran todos los préstamos de los que eran responsables (esa era la pregunta inicial). Luego se les preguntó de forma explícita si eran los únicos responsables de reembolsarlos o si compartían esa responsabilidad con otra persona. La información que se indica en este cuadro se obtuvo a partir de la última pregunta e incluye no solo los préstamos de los cuales una persona o una pareja es responsable, sino también los préstamos en los cuales la responsabilidad del reembolso se comparte con alguien que no es la pareja (que puede ser integrante del hogar o no). Estos últimos constituyen pocos casos en términos relativos.

8 Aquí se incluyen también algunos casos de financiamiento directo de vivienda ofrecido por constructores, que no se adecuaban a ninguna de las demás categorías. También es posible que en esta categoría se sobrestimen los préstamos formales, en la medida en que los préstamos en especie que otorgan las tiendas pequeñas del sector informal no se pueden desagregar. No obstante, el hecho de que la gran mayoría de los préstamos de esta categoría se obtengan para adquirir bienes duraderos nos da la seguridad de que es correcto categorizarlos como préstamos formales.

9 El principal banco estatal que otorga préstamos a los particulares es el Banco del Instituto Ecuatoriano de Seguridad Social (BIESS), que es un banco público autónomo que solo otorga préstamos a sus socios, en particular hipotecas para financiar la adquisición o la construcción de vivienda. 


\section{Cuadro 4}

Ecuador: distribución de los préstamos según el responsable de reembolsar la deuda y la fuente, 2010

(En porcentajes)

\begin{tabular}{|c|c|c|c|c|c|}
\hline \multirow[b]{2}{*}{ Fuente } & \multicolumn{4}{|c|}{ Parte responsable } & \multirow{2}{*}{ Total de préstamos } \\
\hline & Solo el hombre & Solo la mujer & Pareja principal & $\begin{array}{l}\text { Otros préstamos } \\
\text { conjuntos }\end{array}$ & \\
\hline Banco estatal & 11,7 & 8,7 & 6,8 & 9,5 & 9,4 \\
\hline Banco privado & 12,1 & 12,2 & 21,1 & 18,2 & 14,6 \\
\hline Cooperativa o mutual crediticia & 11,5 & 11,1 & 25,7 & 24,3 & 15,4 \\
\hline $\begin{array}{l}\text { Otra institución privada u } \\
\text { organización no gubernamental }\end{array}$ & 2,3 & 5,8 & 2,1 & 8,5 & 3,6 \\
\hline Comercio o tienda & 27,6 & 25,2 & 18,6 & 24,8 & 24,4 \\
\hline Tarjeta de crédito & 4,2 & 3,2 & 1,3 & 0,0 & 3,0 \\
\hline Subtotal de préstamos formales & 69,4 & 66,3 & 75,6 & 85,3 & 70,3 \\
\hline Grupo informal & 0,1 & 4,3 & 2,4 & 0,0 & 2,1 \\
\hline Prestamista & 5,0 & 3,8 & 3,8 & 2,1 & 4,2 \\
\hline Empleador & 3,2 & 0,6 & 0,8 & 0,0 & 1,6 \\
\hline Amigo & 13,6 & 9,7 & 5,9 & 5,1 & 10,0 \\
\hline Familiar & 7,6 & 15,1 & 11,4 & 7,5 & 11,2 \\
\hline Otro & 1,1 & 0,4 & 0,1 & 0,0 & 0,6 \\
\hline Subtotal de préstamos informales & 30,6 & 33,7 & 24,4 & 14,7 & 29,7 \\
\hline$\underline{n}$ & 676 & 612 & 453 & 50 & 1791 \\
\hline $\mathrm{N}$ & 807306 & 758834 & 566579 & 55980 & 2188699 \\
\hline
\end{tabular}

Fuente: Elaboración propia, sobre la base de Encuesta Activos FLACSO-Florida (EAFF), 2010 [en línea] http://www. flacsoandes.edu.ec/pagina/60759-documentos-de-encuesta-activos-flacso-florida.

Nota: $F(2,86,609,89)=2,97, p=0,033$.

En general, los préstamos pendientes de las parejas y otros préstamos conjuntos tienen más probabilidades de haberse obtenido de fuentes formales que los préstamos de los cuales el único responsable es un hombre o una mujer. Esto se debe en parte a que es más probable que las fuentes formales de crédito respeten las normas jurídicas y exijan que, al otorgar un préstamo a una persona casada, esta lo firme junto con su cónyuge. No obstante, el que se otorguen préstamos a las parejas también podría ser reflejo de una preferencia institucional: los hogares en los que hay dos ingresos, por ejemplo, se consideran más solventes. Como se observa en el cuadro 4, los bancos privados y las cooperativas son mayoritarios entre las fuentes que otorgan préstamos a las parejas y otros préstamos conjuntos, en comparación con la distribución de los préstamos individuales.

En lo que respecta a las diferencias de género (al comparar los préstamos de los cuales un hombre solo o una mujer sola son responsables), los bancos estatales representan una proporción mayor de préstamos de los cuales un hombre solo es responsable, mientras que las organizaciones no gubernamentales representan una proporción mayor de los préstamos otorgados a las mujeres solas. Los préstamos de los grupos de crédito informal también son más comunes entre los otorgados a las mujeres solas, mientras que los préstamos de empleadores se otorgan más habitualmente a los hombres solos. Esto refleja el hecho de que la proporción de hombres empleados es mayor que la de las mujeres. Por último, es interesante destacar que, cuando las mujeres piden un préstamo en forma individual, recurren más a los familiares, mientras que los hombres recurren más a los amigos como fuente en este caso. 


\section{La finalidad de los préstamos}

Se declararon 1.821 préstamos que tenían un solo destino y, entre ellos, el 68\% se obtuvieron con el fin de acumular activos y el 32\% para pagar gastos. Como se observa en el gráfico 2, la distribución de los préstamos destinados a activos o a gastos exhibe diferencias estadísticamente significativas entre los quintiles de riqueza. Los hogares del quintil más pobre tienen muchas más probabilidades de obtener préstamos para pagar gastos que los de los demás quintiles, que muestran una inclinación a obtenerlos para acumular activos. Se trata de un hallazgo que preocupa de forma especial, ya que sugiere que los préstamos que obtienen los pobres en activos tienen menos probabilidades de generar un flujo de ingresos a futuro, por lo que es posible que estas personas tengan dificultades para reembolsarlos. Este es un factor que examinaremos.

\section{Gráfico 2}

Ecuador: proporción de préstamos destinados a activos y a gastos por quintil de riqueza neta del hogar, 2010

(En porcentajes)

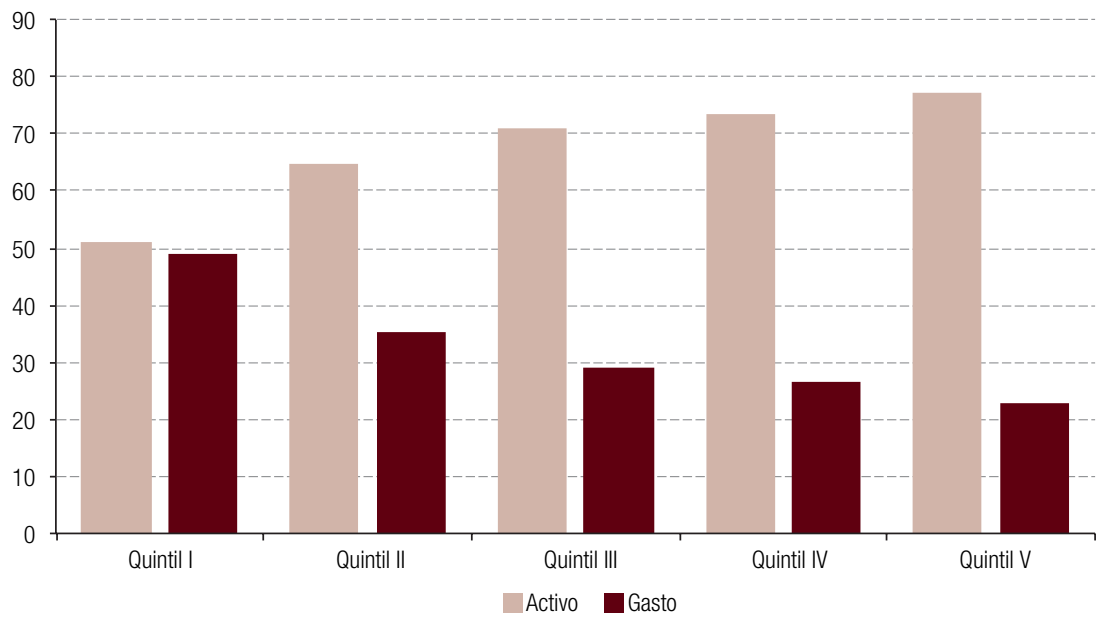

Fuente: Elaboración propia, sobre la base de Encuesta Activos FLACSO-Florida (EAFF), 2010 [en línea] http://www. flacsoandes.edu.ec/pagina/60759-documentos-de-encuesta-activos-flacso-florida.

Nota: $\quad F(2,57,546,71), p=0,000$.

En el cuadro 5 se ofrece un desglose más detallado de cómo incide la deuda de los hogares según su finalidad entre aquellos que tienen préstamos. En este cuadro se toma en cuenta que los hogares pueden tener varios préstamos y que estos se pueden haber obtenido con distintos fines. Se observa que, en términos generales, las finalidades más frecuentes son la adquisición de bienes duraderos de consumo (28\%) y, de forma explícita, para un negocio (27\%). A esto le siguen en frecuencia los préstamos obtenidos para adquirir un terreno para vivienda, o adquirir, mejorar o ampliar una vivienda (19\%), para satisfacer las necesidades diarias (15\%) y para cubrir gastos de salud (10\%).

Una las diferencias de clase más llamativas es la mayor frecuencia con la que los hogares del 40\% más pobre de la distribución de la riqueza obtienen préstamos para adquirir bienes duraderos (como una cocina, un televisor o un refrigerador), así como para satisfacer las necesidades diarias y cubrir los costos de salud. Por el contrario, entre los hogares que pertenecen al $40 \%$ más rico, lo más 
frecuente es que soliciten préstamos para adquirir su vivienda o mejorarla, o para hacer negocios. Los hogares más ricos también tienen muchas más probabilidades de solicitar un préstamo para adquirir un vehículo, mientras que los más pobres tienen más probabilidades de obtener un préstamo para pagar gastos de educación. Según lo que sugiere este análisis, en comparación con los hogares más pobres, es más probable que los más ricos se endeuden para adquirir activos que generarán ingresos de forma directa o servirán de garantía para adquirir otros préstamos en el futuro. Cabe destacar, sin embargo, que los hogares de los quintiles I y $\vee$ tienen las mismas probabilidades de solicitar un préstamo para pagar préstamos anteriores. El reciclaje de préstamos a menudo se señala como un posible síntoma de sobreendeudamiento (Schicks, 2013b).

\section{Cuadro 5}

Ecuador: incidencia de los préstamos entre los hogares que los tienen, por finalidad y quintil de riqueza neta del hogar, 2010

(En porcentajes)

\begin{tabular}{|c|c|c|c|c|c|c|}
\hline \multirow{2}{*}{ Finalidad } & \multicolumn{5}{|c|}{ Quintil } & \multirow{2}{*}{$\begin{array}{c}\text { Total de hogares } \\
\text { con préstamos }\end{array}$} \\
\hline & 1 & 2 & 3 & 4 & 5 & \\
\hline Vivienda/terreno & 3,9 & 16,6 & 14,0 & 28,1 & 29,8 & 19,2 \\
\hline Terrenos agrícolas & 0,0 & 0,2 & 0,6 & 0,7 & 3,3 & 1,1 \\
\hline Otros bienes raíces & 6,1 & 2,2 & 5,1 & 6,7 & 6,2 & 5,3 \\
\hline Negocios & 21,1 & 17,8 & 31,3 & 25,4 & 37,5 & 27,1 \\
\hline Equipamiento e instalaciones agropecuarias & 0,4 & 0,9 & 0,0 & 0,2 & 1,6 & 0,6 \\
\hline Animales & 0,8 & 0,8 & 1,7 & 0,6 & 1,6 & 1,1 \\
\hline Insumos agrícolas & 0,4 & 3,6 & 3,7 & 0,3 & 1,6 & 1,9 \\
\hline Bienes duraderos & 33,1 & 39,6 & 30,4 & 19,9 & 18,1 & 27,6 \\
\hline Vehículos & 0,6 & 2,3 & 3,4 & 9,2 & 11,8 & 5,8 \\
\hline Deuda relacionada con activos & 60,9 & 73,4 & 77,5 & 75,4 & 84,6 & 74,9 \\
\hline Necesidades diarias & 22,7 & 21,0 & 11,8 & 13,9 & 8,2 & 15,1 \\
\hline Salud & 18,9 & 11,0 & 9,2 & 5,5 & 7,7 & 10,2 \\
\hline Educación & 9,9 & 10,0 & 5,2 & 4,4 & 7,3 & 7,3 \\
\hline Celebraciones & 3,3 & 1,3 & 0,8 & 1,7 & 0,5 & 1,5 \\
\hline Pago de otra deuda & 11,1 & 5,3 & 7,8 & 6,6 & 11,4 & 8,5 \\
\hline Otro & 5,8 & 5,5 & 6,8 & 7,5 & 3,5 & 5,8 \\
\hline Deuda relacionada con gastos & 59,4 & 43,9 & 36,6 & 33,2 & 30,4 & 40,0 \\
\hline Cualquier deuda & 43,6 & 45,3 & 48,0 & 49,9 & 55,1 & 48,4 \\
\hline n (con cualquier préstamo) & 253 & 266 & 272 & 249 & 318 & 1358 \\
\hline N (con cualquier préstamo) & 291826 & 302798 & 321428 & 333354 & 368445 & 1617851 \\
\hline
\end{tabular}

Fuente: Elaboración propia, sobre la base de Encuesta Activos FLACSO-Florida (EAFF), 2010 [en línea] http://www. flacsoandes.edu.ec/pagina/60759-documentos-de-encuesta-activos-flacso-florida.

En lo que respecta a quién es responsable de estos préstamos, en el gráfico 3 se observa que, en comparación con los prestatarios individuales, es mucho más probable que las parejas y otros prestatarios conjuntos tengan préstamos relacionados con la adquisición de activos y no con el pago de gastos. Además, las mujeres que solicitan préstamos de forma individual tienen más probabilidades que cualquier otro grupo de tener deudas asociadas con gastos en lugar de activos. 


\section{Gráfico 3}

Ecuador: préstamos destinados a activos y a gastos según quién es responsable, 2010

(En porcentajes)

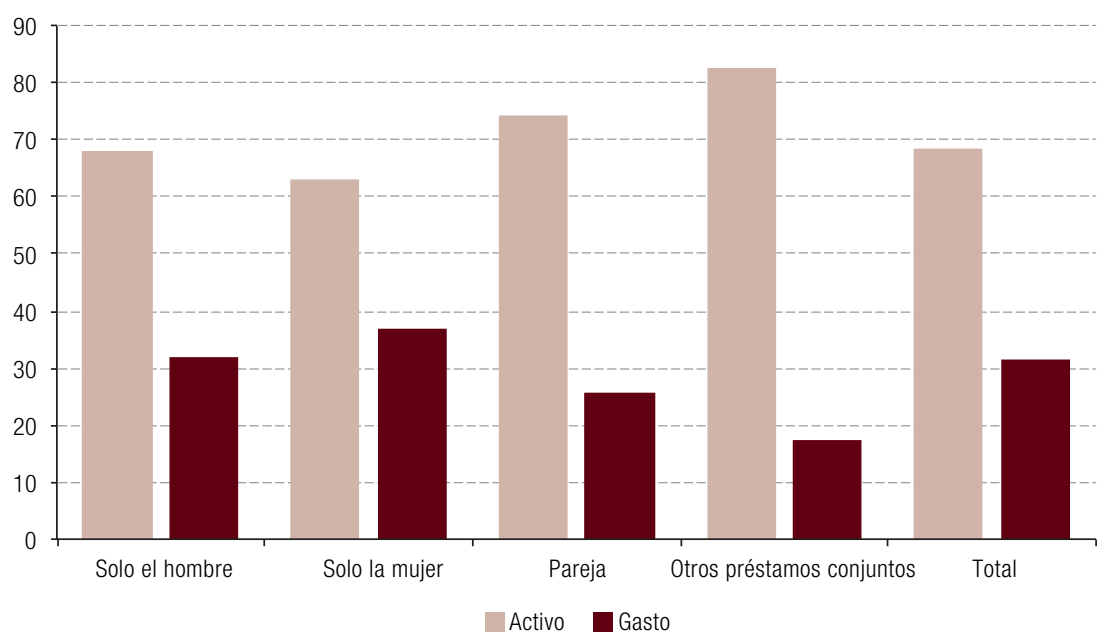

Fuente: Elaboración propia, sobre la base de Encuesta Activos FLACSO-Florida (EAFF), 2010 [en línea] http://www. flacsoandes.edu.ec/pagina/60759-documentos-de-encuesta-activos-flacso-florida.

Nota: $\quad F(2,54,540,3), p=0,015$.

Por último, en el gráfico 4 se presenta la distribución de los préstamos según la finalidad y la fuente. Como se puede observar, mientras que los préstamos destinados a la adquisición de activos tienen muchas más probabilidades de obtenerse de fuentes formales de crédito, es más probable que los préstamos destinados a gastos se obtengan de fuentes informales.

Gráfico 4

Ecuador: préstamos por finalidad y fuente, 2010

(En porcentajes)

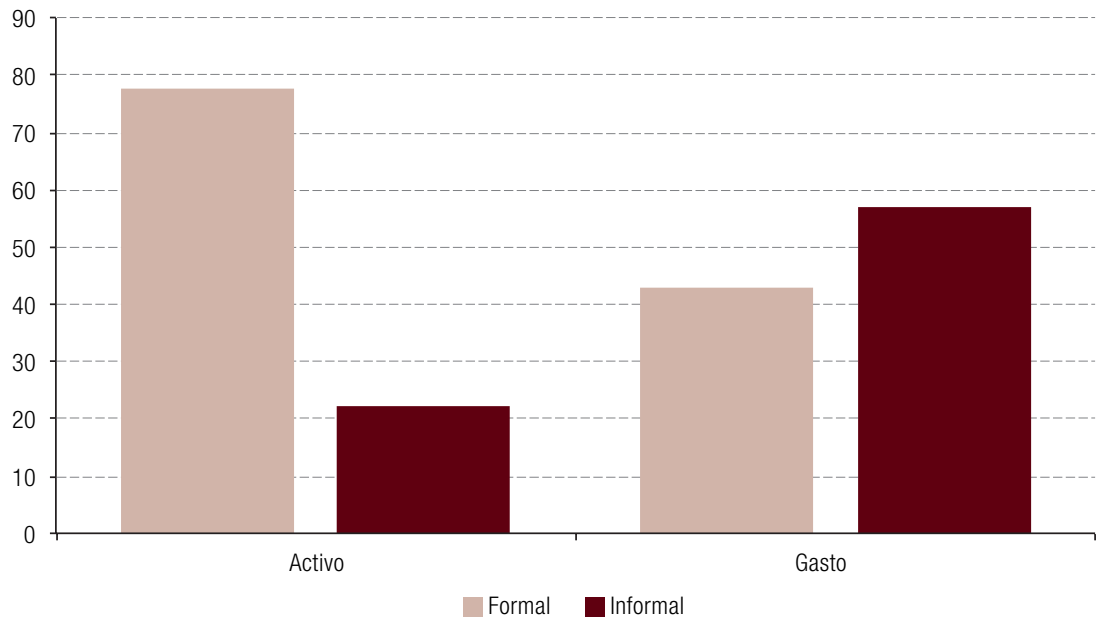

Fuente: Elaboración propia, sobre la base de Encuesta Activos FLACSO-Florida (EAFF), 2010 [en línea] http://www. flacsoandes.edu.ec/pagina/60759-documentos-de-encuesta-activos-flacso-florida.

Nota: $F(1,213), p=0,000$. 


\section{La probabilidad de obtener un préstamo para acumular activos}

Ahora nos referiremos a la probabilidad de que una persona adquiera un préstamo para adquirir activos. Para llevar a cabo un análisis desde la perspectiva del género, se considera que una persona pide prestado para adquirir activos ya sea que el préstamo a su cargo se haya obtenido de forma individual o conjunta. Hacemos regresiones logísticas en relación con los hombres y las mujeres por separado. Las variables que nos interesan son las siguientes: i) si se trata de un perceptor de ingresos, definido como una persona que tiene un empleo remunerado (ya sea empleador, trabajador por cuenta propia o cualquier tipo de trabajador que perciba una remuneración), o si se trata de un trabajador familiar no remunerado, de alguien que está desempleado o de una persona que no es económicamente activa; ii) si se tiene una cuenta de ahorros formal; iii) si se es integrante de una red social, y iv) el quintil de riqueza neta del hogar al cual la persona pertenece.

Partimos de la hipótesis de que las personas que perciben ingresos de forma directa se consideran más solventes que aquellas que no lo hacen, puesto que tienen medios verificables con los cuales pagar los préstamos. En algunos casos, una constancia de empleo o de titularidad de un negocio puede ser garantía suficiente, en particular entre las cooperativas de ahorro y crédito ${ }^{10}$. Dado que obtener un préstamo puede estar vinculado con tener una relación previa con el prestamista y que tener ahorros puede servir como garantía, prevemos que aquellos que tienen una cuenta de ahorros formal tienen más probabilidades de obtener préstamos con la finalidad de acumular activos (CAF, 2011). Es habitual que los bancos privados y las cooperativas de ahorro y crédito del Ecuador exijan que los posibles prestatarios tengan una cuenta de ahorros o mantengan un saldo mínimo en su cuenta. Esas condiciones también pueden reducir el costo de los préstamos. Además, contar con ahorros formales podría reducir la necesidad de obtener crédito de corto plazo, por lo que los titulares de las cuentas tendrían más probabilidades de solicitar préstamos para adquirir activos (Kast y Pomeranz, 2014).

Suponemos que las personas que integran un grupo o una red social tienen mayor acceso a la información acerca de la disponibilidad y las condiciones del crédito, por lo que es más probable que tengan préstamos destinados a activos (Fletschner y Mesbah, 2011). Además, integrar un grupo puede aumentar las posibilidades de conseguir a alguien que garantice el préstamo, requisito que se debe cumplir en el Ecuador para obtener préstamos de los bancos privados y de la mayoría de las cooperativas de ahorro y crédito. Los grupos más habituales a los que pertenecen las mujeres encuestadas son los religiosos, seguidos de las asociaciones de padres y los grupos comunitarios. En el caso de los hombres, el orden es diferente: sindicatos, asociaciones deportivas y grupos comunitarios. Por último, prevemos que las personas que provienen de hogares ricos en activos tienen más probabilidades de acceder a préstamos para adquirirlos que aquellas que provienen de hogares pobres en activos, dado que es más fácil para las primeras ofrecer garantía a fin de obtener el préstamo.

Además de las variables demográficas habituales, hacemos ajustes para tomar en cuenta si una persona también tiene algún préstamo destinado a gastos, a fin de evaluar si obtener préstamos destinados a activos se asocia con obtener menos préstamos destinados a gastos y viceversa. Las estadísticas que describen estas y otras variables se proporcionan en el cuadro 6.

\footnotetext{
${ }^{10}$ Análisis de los sitios web de las más grandes entre las 39 cooperativas de ahorro y crédito ecuatorianas que se mencionan en MIX Market (consultados en enero de 2015).
} 


\section{Cuadro 6}

Ecuador: estadísticas descriptivas de regresión

\begin{tabular}{|c|c|c|c|c|}
\hline \multirow{3}{*}{ Variable } & \multicolumn{4}{|c|}{ Sexo } \\
\hline & \multicolumn{2}{|c|}{ Mujeres } & \multicolumn{2}{|c|}{ Hombres } \\
\hline & Estimación & Error estándar & Estimación & Error estándar \\
\hline Préstamo destinado a activos ${ }^{\star \star \star}$ & 26,7 & & 34,3 & \\
\hline Edad $^{\star \star *}$ & 43,43 & 0,45 & 45,64 & 0,52 \\
\hline \multicolumn{5}{|l|}{ Raza } \\
\hline Blanco o mestizo & 89,9 & & 88,6 & \\
\hline Indígena & 4,9 & & 5,6 & \\
\hline Afroecuatoriano & 5,2 & & 5,8 & \\
\hline \multicolumn{5}{|l|}{ Educación* } \\
\hline No terminó la primaria & 20,4 & & 17,6 & \\
\hline Terminó la primaria & 29,2 & & 30,7 & \\
\hline Terminó la secundaria & 36,9 & & 36,1 & \\
\hline Estudios posteriores a la secundaria & 13,5 & & 15,5 & \\
\hline \multicolumn{5}{|l|}{ Estado civil ${ }^{\star \star *}$} \\
\hline Casado & 48,0 & & 59,8 & \\
\hline Unión consensual & 25,3 & & 31,2 & \\
\hline Nunca ha estado en pareja & 3,9 & & 2,7 & \\
\hline Separado, divorciado o viudo & 22,8 & & 6,4 & \\
\hline Perceptor de ingresos ${ }^{\star \star \star}$ & 59,9 & & 90,9 & \\
\hline Urbano & 75,1 & & 75,1 & \\
\hline Deuda relacionada con gastos ${ }^{\star \star *}$ & 13,9 & & 16,5 & \\
\hline \multicolumn{5}{|l|}{ Quintiles $^{\star \star \star}$} \\
\hline 1 & 20,5 & & 18,2 & \\
\hline$\|$ & 20,0 & & 21,7 & \\
\hline III & 19,9 & & 20,8 & \\
\hline IV & 20,0 & & 18,7 & \\
\hline V & 19,7 & & 20,6 & \\
\hline Integra un grupo*** & 18,4 & & 25,5 & \\
\hline Tamaño del hogar** & 4,24 & 0,04 & 4,33 & 0,06 \\
\hline Cuenta de ahorros formal ${ }^{\star \star \star}$ & 30,6 & & 43,7 & \\
\hline $\mathrm{n}$ & \multicolumn{2}{|c|}{2656} & \multicolumn{2}{|c|}{2012} \\
\hline N & \multicolumn{2}{|c|}{3081255} & \multicolumn{2}{|c|}{2298877} \\
\hline
\end{tabular}

Fuente: Elaboración propia, sobre la base de Encuesta Activos FLACSO-Florida (EAFF), 2010 [en línea] http://www. flacsoandes.edu.ec/pagina/60759-documentos-de-encuesta-activos-flacso-florida.

Nota: Las estimaciones de las variables categóricas se presentan como porcentajes, y las de las variables continuas como medias. ${ }^{* \star *} p<0,01$; ${ }^{* \star} p<0,05 ;{ }^{*} p<0,10$, en lo que respecta a las diferencias entre mujeres y hombres.

Una diferencia clara entre los géneros es que los hombres tienen más probabilidades que las mujeres de haber obtenido un préstamo destinado a activos, de percibir ingresos laborales, de integrar un grupo y de tener una cuenta de ahorros formal. La distribución de la educación y el estado civil también difiere entre los hombres y las mujeres: estas últimas tienen menos probabilidades de haber terminado la escuela primaria y los primeros tienen más probabilidades de haber estudiado luego de terminar la secundaria; además, en comparación con los hombres, es mucho más probable que las mujeres sean separadas, divorciadas o viudas. 
Los resultados que aparecen en el cuadro 7 muestran que, entre las variables que nos interesan, contar con una cuenta de ahorros formal es el factor que se correlaciona de forma más positiva y significativa con obtener préstamos para adquirir activos. Este factor aumenta un $18 \%$ y un $20 \%$, respectivamente, la probabilidad de que las mujeres y los hombres tengan un préstamo destinado a activos. Tener un empleo que genera ingresos solo se asocia con tener un préstamo destinado a activos en el caso de las mujeres: aumenta un $14,2 \%$ su probabilidad de tenerlo. Es probable que el hecho de que en los hombres no se observe una asociación significativa con esta variable se deba a que la abrumadora mayoría de ellos se declaran perceptores de ingresos, por lo que hay menos posibilidades de que esta variable permita establecer una distinción entre los hombres que tienen préstamos destinados a activos y los que no los tienen.

Cuadro 7

Ecuador: resultados de la regresión logística de la probabilidad de obtener un préstamo para acumular activos

\begin{tabular}{|c|c|c|c|c|c|c|}
\hline \multirow{3}{*}{ Variable } & \multicolumn{6}{|c|}{ Sexo } \\
\hline & \multicolumn{3}{|c|}{ Mujeres } & \multicolumn{3}{|c|}{ Hombres } \\
\hline & $\mathrm{dy} / \mathrm{dx}$ & Error estándar & $\mathrm{p}$ & $\mathrm{dy} / \mathrm{dx}$ & Error estándar & $p$ \\
\hline Edad & $-0,002$ & 0,001 & & $-0,005$ & 0,001 & *** \\
\hline \multicolumn{7}{|l|}{ Raza } \\
\hline Blanco o mestizo & Ref. & Ref. & & Ref. & Ref. & \\
\hline Indígena & 0,094 & 0,082 & & $-0,037$ & 0,057 & \\
\hline Afroecuatoriano & 0,154 & 0,058 & 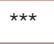 & 0,151 & 0,059 & ** \\
\hline \multicolumn{7}{|l|}{ Educación } \\
\hline No terminó la primaria & Ref. & Ref. & & Ref. & Ref. & \\
\hline Terminó la primaria & 0,035 & 0,037 & & $-0,003$ & 0,046 & \\
\hline Terminó la secundaria & 0,068 & 0,046 & & 0,021 & 0,034 & \\
\hline Estudios posteriores a la secundaria & 0,040 & 0,059 & & 0,011 & 0,047 & \\
\hline \multicolumn{7}{|l|}{ Estado civil } \\
\hline Casado & Ref. & Ref. & & Ref. & Ref. & \\
\hline Unión consensual & $-0,011$ & 0,029 & & $-0,069$ & 0,031 & ** \\
\hline Nunca ha estado en pareja & $-0,124$ & 0,043 & $* * *$ & $-0,244$ & 0,052 & *** \\
\hline Separado, divorciado o viudo & 0,003 & 0,026 & & $-0,040$ & 0,048 & \\
\hline Perceptor de ingresos & 0,142 & 0,019 & $* * *$ & $-0,022$ & 0,064 & \\
\hline Urbano & $-0,028$ & 0,034 & & $-0,019$ & 0,029 & \\
\hline Deuda relacionada con gastos & $-0,017$ & 0,034 & & $-0,117$ & 0,030 & *** \\
\hline \multicolumn{7}{|l|}{ Quintiles de riqueza neta del hogar } \\
\hline । & Ref. & Ref. & & Ref. & Ref. & \\
\hline ॥ & 0,010 & 0,036 & & $-0,002$ & 0,043 & \\
\hline III & 0,090 & 0,037 & 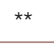 & 0,068 & 0,041 & * \\
\hline IV & 0,115 & 0,047 & $\star \star *$ & 0,070 & 0,038 & * \\
\hline V & 0,144 & 0,036 & $* * *$ & 0,063 & 0,053 & \\
\hline Integra un grupo & 0,048 & 0,033 & & 0,087 & 0,030 & *** \\
\hline Tamaño del hogar & 0,000 & 0,006 & & 0,013 & 0,008 & * \\
\hline Cuenta de ahorros formal & 0,181 & 0,027 & 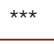 & 0,196 & 0,024 & *** \\
\hline$F(20,194)$ & & $20,31^{\star \star \star}$ & & & $10,55^{\star \star \star}$ & \\
\hline$n$ & & 2656 & & & 2012 & \\
\hline $\mathrm{N}$ & & 3081255 & & & 2298877 & \\
\hline
\end{tabular}

Fuente: Elaboración propia, sobre la base de Encuesta Activos FLACSO-Florida (EAFF), 2010 [en línea] http://www. flacsoandes.edu.ec/pagina/60759-documentos-de-encuesta-activos-flacso-florida.

Nota: $\quad{ }^{* \star *} p<0,01 ;{ }^{* *} p<0,05 ;{ }^{*} p<0,10$. 
Por otra parte, ser integrante de un grupo solo se asocia con tener un préstamo destinado a activos en el caso de los hombres: aumentan un 8,7\% las probabilidades de que estos pidan un préstamo con ese fin. Este resultado, combinado con la conclusión mencionada anteriormente de que las mujeres y los hombres suelen pertenecer a diferentes tipos de grupos, sugiere que el tipo de grupo al cual una persona pertenece puede incidir en cuanto a que este sea una fuente de información crediticia y de posibles garantes de un préstamo. En el caso de las mujeres, pertenecer a alguno de los quintiles de riqueza del hogar situados en el $60 \%$ superior de la distribución se asocia con la obtención de préstamos para adquirir activos. En el caso de los hombres, por el contrario, los que pertenecen al 20\% superior no exhiben diferencias significativas con los que pertenecen al quintil más pobre en lo que respecta a las probabilidades de tener un préstamo destinado a activos. La magnitud del efecto también sugiere que la riqueza del hogar es más importante para las mujeres que para los hombres en cuanto a la capacidad para adquirir préstamos destinados a acumular activos.

Tener deudas destinadas a gastos a veces se asocia con tener menos deudas destinadas a activos solo en el caso de los hombres, lo que sugiere que tal vez haya más probabilidades de que las mujeres tengan ambos tipos de préstamos o los usen con más frecuencia para más de un fin. Nunca haber estado en pareja disminuye las probabilidades de solicitar un préstamo para adquirir activos en comparación con estar casado, tanto en el caso de los hombres como de las mujeres. Es interesante observar que estar en una unión consensual disminuye esta probabilidad en comparación con estar casado solo en el caso de los hombres. Ser afroecuatoriano (en lugar de blanco o mestizo) aumenta la probabilidad de tener deuda destinada a activos tanto en el caso de los hombres como de las mujeres ${ }^{11}$. Ninguna de las variables categóricas relativas al nivel de educación es estadísticamente significativa, mientras que la edad se asocia de forma negativa con la deuda destinada a activos solo en el caso de los hombres.

\section{El endeudamiento de los hombres y las mujeres}

En la literatura hay un debate considerable sobre cómo se debería medir el "sobreendeudamiento" y cuándo este constituye un problema (Betti y otros, 2007; Disney, Bridges y Gathergood, 2008; Schicks, 2013a). El modo más habitual de medirlo es mediante la carga del servicio de deuda de los hogares, que se mide como la proporción del ingreso mensual del hogar que representa el flujo del servicio de deuda (intereses más amortización del préstamo). Normalmente, una relación del 50\% o más entre la deuda y los ingresos se considera problemática. No obstante, en esta medición no se toma en cuenta que, según la hipótesis del ciclo de vida o del ingreso permanente, la relación óptima puede variar durante el ciclo de vida de una persona, por lo que tal vez no sea un buen indicador del sobreendeudamiento. Una medida alternativa es la relación entre la deuda y los activos, o entre la deuda y el patrimonio neto, que permite medir el total de la deuda y los activos del hogar. A esta medida se la critica, a su vez, porque en ella no se toman en cuenta los recursos que los hogares podrían tener en un momento particular para hacer frente al servicio de la deuda. Además, en los países en desarrollo se hacen pocas encuestas de hogares en las que se recoja información acerca de la propiedad de los activos.

A las dos medidas anteriores también se las ha criticado por estar relacionadas con una perspectiva de gestión del riesgo - que conviene a quienes otorgan préstamos-, en lugar de enfocarse en proteger al cliente. Schicks (2013a y 2013b) dice que la última se centra en los sacrificios que los hogares y las personas a veces deben hacer para pagar sus deudas. Plantea que la mejor manera de medir el sobreendeudamiento es determinar qué proporción de una población dada tiene dificultades para pagar sus deudas, hace sacrificios inaceptables para pagarlas o hace sacrificios que

\footnotetext{
${ }^{11}$ No obstante, dada la proporción relativamente pequeña de afroecuatorianos en la muestra, es posible que esta asociación no sea válida.
} 
señalan problemas estructurales, como la pérdida de activos debida al incumplimiento del pago de un préstamo, el reciclaje de préstamos o la necesidad de vender o empeñar activos para pagar.

Si bien en nuestra encuesta no se recogió información acerca de la importancia del pago de las deudas en términos del sacrificio relativo que conlleva, es una de las primeras encuestas en los países en desarrollo que mide con rigor la propiedad de los activos a nivel individual junto con la deuda. Nuestro aporte radica sobre todo en ofrecer indicadores de la relación entre la deuda y la riqueza neta de los hombres y las mujeres. Además, como se señaló anteriormente, el reciclaje de los préstamos no es raro en el Ecuador, donde el 8,5\% de los hogares ha solicitado un préstamo para pagar otros anteriores (véase el cuadro 5).

En conjunto, los hogares del Ecuador no parecen estar muy endeudados, ya que la deuda total representa solo el 5,8\% del patrimonio neto total. Según Shorrocks, Davies y Lluberas (2012), en los países en desarrollo, esta relación suele ser inferior al 10\%, por lo que las estimaciones relativas al Ecuador se encuentran dentro del rango esperado. Como se observa en el cuadro 8, la relación que les corresponde a los encuestados es levemente superior $(6,6 \%)$ a la relación entre la deuda y la riqueza de los hogares ${ }^{12}$, y la relación entre la deuda y la riqueza neta de los hombres es superior a la de las mujeres.

\section{Cuadro 8}

Ecuador: relación entre la deuda y la riqueza neta de los encuestados por sexo y quintil de riqueza neta del hogar, 2010

\begin{tabular}{lccccccc}
\hline \multirow{2}{*}{ Sexo } & \multicolumn{7}{c}{ Quintil } \\
\cline { 2 - 7 } & I & II & III & IV & V & Total \\
\hline Hombre & $-52,452$ & 0,232 & 0,102 & 0,091 & 0,053 & 0,079 \\
\hline Mujer & 3,279 & 0,107 & 0,067 & 0,072 & 0,038 & 0,056 \\
\hline Total & 9,375 & 0,160 & 0,082 & 0,079 & 0,046 & 0,066 \\
\hline
\end{tabular}

Fuente: Elaboración propia, sobre la base de Encuesta Activos FLACSO-Florida (EAFF), 2010 [en línea] http://www. flacsoandes.edu.ec/pagina/60759-documentos-de-encuesta-activos-flacso-florida.

Un problema que surge al medir esta relación y compararla entre diferentes grupos es que, si el patrimonio neto es negativo (porque el valor de la deuda pendiente es mayor que el valor de los activos de una persona), la relación entre la deuda y la riqueza neta también será negativa. En nuestra muestra, aproximadamente el $5 \%$ de los encuestados declaran tener una riqueza neta negativa, y la incidencia de esto es mayor en los hombres (6,3\%) que en las mujeres (4\%). Además, los que pertenecen al quintil más pobre tienen muchas más probabilidades de que su riqueza neta sea negativa que los que son más ricos: el $21,3 \%$ de los hombres del quintil I (frente a menos del $5 \%$ de los que pertenecen a los quintiles II a V), y el $12,6 \%$ de las mujeres del quintil I (frente a menos del $3 \%$ de las que pertenecen a todos los demás quintiles). Como se observa en el cuadro 8 , en lo que respecta a la relación agregada entre la deuda y la riqueza neta dentro de cada quintil, los hombres del quintil más pobre tienen una relación negativa, lo que sugiere que, como grupo, son los que tienen el nivel de deuda más opresivo ${ }^{13}$. Además, las mujeres del quintil I tienen la mayor relación agregada entre deuda y riqueza neta, en comparación con las mujeres de todos los demás quintiles.

\footnotetext{
12 Ambas cifras difieren porque en la última solo se incluye la deuda que tenían quienes respondieron en el módulo relativo a la deuda (los adultos principales del hogar). Por consiguiente, al calcular la deuda del encuestado, la que este tenía junto con otro integrante del hogar, como un hijo o una hija, se dividió entre ellos, de modo que solo la mitad de la deuda aparece como correspondiente al encuestado. Los activos cuya propiedad era conjunta se calcularon del mismo modo. Es de esperar que la relación correspondiente a la deuda del hogar sea inferior a la que corresponde a la deuda del encuestado, debido a que el denominador incluye todos los activos que son propiedad de cualquiera de los integrantes del hogar, pero el numerador puede estar subestimado, porque no recogimos información acerca de las deudas de todos los integrantes del hogar.

${ }^{13}$ La relación agregada negativa que corresponde a los hombres del quintil I también es producto del diseño de la muestra, en la que unos pocos hombres de esta categoría representan un peso muy grande. La relación sin ponderar entre la deuda y la riqueza neta de los hombres del quintil I es 4,32, y la de las mujeres, 1,61.
} 
Schicks (2013a) hace un análisis de la literatura sobre microfinanzas y concluye que, si bien es difícil hallar una medida adecuada del sobreendeudamiento que se adecue a todos los casos, hay consenso en que este concepto se aplica mejor cuando el problema es estructural y persistente. Dado que, en comparación con el ingreso actual, la riqueza es un mejor indicador indirecto de los ingresos permanentes, la relación preocupante entre la duda y la riqueza de quienes pertenecen al quintil más pobre sugiere un problema estructural relacionado con la tendencia de los hogares de este quintil a endeudarse para hacer frente a sus gastos, en lugar de hacerlo para acumular activos.

Otro indicio de que hay un problema estructural es el pedir prestado para pagar préstamos anteriores. En términos generales, solo el 3,6\% de los hombres y el 2,8\% de las mujeres declararon haber obtenido un préstamo para pagar otro anterior. Un examen más minucioso sugiere que los que tienen más probabilidades de "reciclar" sus deudas son aquellos que también declaran una riqueza neta negativa. Además, si bien los hombres tienen más probabilidades que las mujeres de tener una riqueza neta negativa, una mayor proporción de las mujeres cuya riqueza neta es negativa declara haber obtenido préstamos para pagar su deuda (20,2\%), en comparación con los hombres de la misma categoría (13,5\%). Esto sugiere que las mujeres tienen más probabilidades de caer en una trampa de endeudamiento en la que piden prestado para pagar préstamos.

\section{Conclusiones}

En el presente artículo se ha proporcionado información empírica que respalda lo que plantea Figueroa (2011) acerca de la estructura segmentada de los mercados crediticios de América Latina. En el caso del Ecuador, hemos demostrado que, si bien hoy en día el sector formal es la principal fuente de préstamos en todos los quintiles, los pobres tienen muchas más probabilidades que los ricos de recurrir a fuentes informales. Si bien no tenemos información primaria acerca del interés que se paga por esos préstamos, el mayor acceso de los quintiles más ricos a los préstamos que otorgan los bancos privados y estatales, sumado a las menores tasas de interés que estos cobran, cuyo máximo se establece por ley, ilustran lo que Figueroa sugiere: que la riqueza en activos permite acceder a condiciones privilegiadas de préstamo y engendra riqueza.

Hemos llevado este análisis de la desigualdad económica un paso más allá al considerar la finalidad de los préstamos. Hemos mostrado que los ricos tienen muchas más probabilidades que los pobres de obtener préstamos con el fin de acumular activos. Quienes pertenecen al quintil más pobre y las mujeres solas tienen más probabilidades que los demás de obtener préstamos para pagar gastos, y los préstamos que obtienen para adquirir activos también tienen menos probabilidades de generar un flujo de ingresos en el corto plazo. No sorprende que el quintil más pobre acabe teniendo la relación más preocupante entre la deuda y la riqueza neta, lo que sugiere que los préstamos de estas personas podrían encaminarlas hacia una trampa de endeudamiento insostenible. Además, si bien los hombres más pobres tienen la relación más preocupante entre la deuda y la riqueza neta, son las mujeres más pobres, entre las personas cuya riqueza neta es negativa, las que tal vez tengan el grado más elevado de endeudamiento excesivo, dado que es más frecuente que obtengan préstamos para pagar otros anteriores.

¿Significa esto que siempre es desaconsejable obtener préstamos para pagar gastos? No lo creemos así, dado que es bien sabido que el acceso a ese tipo de crédito desempeña un papel importante para facilitar el consumo y gestionar los riesgos, en particular entre quienes tienen ingresos volátiles. Como lo recomienda Schicks (2013a), las situaciones de sobreendeudamiento exigen un análisis minucioso de sus causas, entre las que se podrían encontrar las perturbaciones externas, el comportamiento de quienes otorgan los préstamos (productos y procedimientos no adecuados) o el comportamiento de los prestatarios. Si la causa está relacionada con el comportamiento de quienes 
otorgan los préstamos, entonces la solución podría ser, como Schicks sugiere, ofrecer un "crédito mejor" y no uno menor.

Según el análisis de regresión que llevamos a cabo, tener una cuenta de ahorros formal es el principal factor que se asocia de forma positiva con la capacidad de los hombres y las mujeres para acceder a los préstamos destinados a la acumulación de activos en el Ecuador. La relación entre tener una cuenta bancaria y acceder al crédito se ha planteado con frecuencia en la literatura (CAF, 2011). Nuestro análisis proporciona pruebas de que esta relación reviste particular importancia cuando se trata de acumular activos, dado que los préstamos que se otorgan con ese fin se concentran en el sector financiero formal. Desde el punto de vista de las políticas, nuestros hallazgos sugieren que la tendencia a "bancarizar a quienes no están bancarizados", que consiste en fomentar las cuentas de ahorros, a la larga podría tener un éxito más amplio que un enfoque que solo se centre en fomentar los préstamos. Además, en la medida en que los ahorros formales reducen la necesidad de recurrir al crédito de corto plazo, deberían facilitar los préstamos destinados a adquirir activos, en lugar de aquellos cuya finalidad es pagar gastos.

Nuestro análisis confirma el papel importante que desempeñan las redes sociales para acceder a la información y a las instituciones de crédito (Fletschner y Mesbah, 2011). No obstante, en el caso del Ecuador, nuestra conclusión solo es válida para el caso de los hombres. Es probable que eso esté relacionado con los diferentes tipos de grupos a los que pertenecen los hombres y las mujeres. Los grupos a los que es más habitual que pertenezcan los hombres son los sindicatos y las asociaciones deportivas y, si bien percibir un ingreso no es un aspecto que distinga a los hombres con capacidad para obtener préstamos destinados a activos, pertenecer a un sindicato sí refleja la importancia del tipo de empleo, en este caso, el empleo en el sector formal y el acceso al sistema de seguridad social. El Banco del Instituto Ecuatoriano de Seguridad Social (BIESS) es una fuente importante de préstamos estatales (véase el cuadro 5), si bien solo pueden acceder a él sus socios que, históricamente, han sido en su mayoría hombres ${ }^{14}$. Por último, el hecho de que una mujer tenga su propia fuente de ingresos es un factor importante que determina la obtención de préstamos para acumular activos. Solo este factor - el ingreso independiente de las mujeres - debería contribuir a la reducción de la desigualdad económica entre los géneros.

\section{Bibliografía}

Banerjee, A.V. y E. Duflo (2010), "Giving credit where it is due", Journal of Economic Perspectives, vol. 24, $N^{\circ}$ 3, Nashville, Tennessee, American Economic Association.

Barham, B., S. Boucher y M. Carter (1996), "Credit constraints, credit unions, and small-scale producers in Guatemala", World Development, vol. 24, № 5, Amsterdam, Elsevier.

Bastiaensen, J. y otros (2013), "After the Nicaraguan non-payment crisis: alternatives to microfinance narcissism", Development and Change, vol. 44, № 4, Wiley.

BCE (Banco Central del Ecuador) (2013), Evolución del volumen de crédito y tasas de interés: análisis del sistema de finanzas públicas y privado del Ecuador, Quito, 2013 [en línea] http://contenido.bce.fin.ec/ documentos/Estadisticas/SectorMonFin/BoletinTasasInteres/ect201312.pdf.

Betti, G. y otros (2007), "Consumer over-indebtedness in the EU: measurement and characteristics", Journal of Economic Studies, vol. 34, № 2.

CAF (Corporación Andina de Fomento) (2011), Servicios financieros para el desarrollo: promoviendo el acceso en América Latina, Bogotá.

CEPAL/CELADE (Comisión Económica para América Latina y el Caribe/Centro Latinoamericano y Caribeño de Demografía-División de Población de la CEPAL) (2007), "Estudio sobre la protección social de la tercera edad en Ecuador", Quito.

\footnotetext{
${ }^{14}$ En 2003, el 40\% de los que estaban inscritos en el sistema de seguridad social eran mujeres (CEPAL/CELADE, 2007).
} 
Collins, D. (2008), "Debt and household finance: evidence from the financial diaries", Development Southern Africa, vol. 25, № 4, Taylor \& Francis.

Da Ros, G. (2003), "El crédito rural y las cooperativas financieras en el Ecuador", Revista de la UNIRCOOP (Red Universitaria de las Américas en Estudios Cooperativos y Asociativismo), vol. 1, No 1.

Davies, J. (2008), "An overview of personal wealth", Personal Wealth from a Global Perspective, J. Davies (ed.), Oxford, Oxford University Press.

De la Torre, A., A. Ize y S. Schmukler (2011), Financial Development in Latin America and the Caribbean: The Road Ahead, Washington, D.C., Banco Mundial.

Deere, C.D. y Z.B. Catanzarite (2016), "Measuring the intra-household distribution of wealth in Ecuador: qualitative insights and quantitative outcomes", Handbook of Research Methods and Applications in Heterodox Economics, F. Lee y B. Conin (eds.), Cheltenham, Edward Elgar.

Deere, C.D. y J. Contreras (2011), Acumulación de activos: una apuesta por la equidad, Quito, FLACSOEcuador [en línea] http://genderassetgap.org.

Disney, R., S. Bridges y J. Gathergood (2008), "Drivers of over-indebtedness. Report to the Department for Business, Enterprise and Regulatory Reform", Universidad de Nottingham.

Doss, C. y otros (2011), The Gender Asset and Gender Wealth Gaps: Evidence from Ecuador, Ghana and Karnataka, India, Bangalore, Indian Institute of Management [en línea] http://genderassetgap.org.

EAFF (Encuesta Activos FLACSO-Florida) (2010) [en línea] http://www.flacsoandes.edu.ec/pagina/60759documentos-de-encuesta-activos-flacso-florida.

Fanelli, J.M. (2011), "Domestic financial development in Latin America", The Oxford Handbook of Latin American Economics, J.A. Ocampo y J. Ros (eds.), Oxford, Oxford University Press.

Figueroa, A. (2011), "La desigualdad del ingreso y los mercados de crédito", Revista CEPAL, № 105 (LC/ G.2508-P), Santiago, Comisión Económica para América Latina y el Caribe (CEPAL).

Fletschner, D. y D. Mesbah (2011), "Gender disparity in access to information: do spouses share what they know?", World Development, vol. 39, № 8, Amsterdam, Elsevier.

Floro, M. y J. Messier (2006), "Tendencias y patrones de crédito entre hogares urbanos pobres en Ecuador", La persistencia de la desigualdad: género, trabajo y pobreza en América Latina, G. Herrera (ed.), Quito, Consejo Nacional de las Mujeres (CONAMU)/FLACSO-Ecuador.

Grown, C. y otros (2015), Who Borrows? An Analysis of Gender, Debt and Assets in Ecuador, Ghana and Karnataka, India, Nueva York, Entidad de las Naciones Unidas para la Igualdad de Género y el Empoderamiento de las Mujeres (ONU-Mujeres).

Guirkinger, C. (2008), "Understanding the coexistence of formal and informal credit markets in Piura, Peru", World Development, vol. 36, № 8, Amsterdam, Elsevier.

INEC (Instituto Nacional de Estadística y Censos) (2006), Bases de datos: Condiciones de vida [en línea] http://www.ecuadorencifras.gob.ec/condiciones-de-vida-ecv-bases-de-datos/.

Jácome, H. (2007), "El sistema financiero y su papel en el desarrollo económico y social", La Tendencia. Revista de Análisis Político, № 4, Quito.

(2005), "Alcance de las microfinanzas en las ciudades de Quito, Guayaquil y Cuenca", Documento de Trabajo, Nº 05/201, Quito, FLACSO-Ecuador.

Jácome, H. y J. Cordovéz (2004), "Microfinanzas en la economía ecuatoriana: una alternativa para el desarrollo", Microfinanzas en la economía ecuatoriana: una alternativa para el desarrollo, H. Jácome, E. Ferraro y J. Sánchez (eds.), Quito, FLACSO-Ecuador.

Kast, F. y D. Pomeranz (2014), "Saving more to borrow less: experimental evidence from access to formal savings accounts in Chile", NBER Working Paper, N²0239, Cambridge, Massachusettes, National Bureau of Economic Research.

Mideros, A. (2010), Crédito y desigualdad. Efecto del acceso a créditos en la brecha de ingreso de los hogares, Quito, FLACSO-Ecuador.

Peck, R. y J. Miller (2006), "Future challenges in Latin American microfinance", An Insider View of Latin American Microfinance, M. Berger, L. Goldmark y T. Miller-Sanabria (eds.), Washington, D.C., Banco Interamericano de Desarrollo.

Portes, A. y K. Hoffman (2003), "La estructura de clases en América Latina: composición y cambios durante la era neoliberal”, Desarrollo Económico, vol. 43, № 171, Buenos Aires, Instituto de Desarrollo Económico y Social.

Readout, B. (2011), "Balancing Outreach and Sustainability: The Double Bottom Line of Microfinance in Ecuador", tesis, Gainesville, Florida, Universidad de Florida. 
RFR (Red Financiera Rural) (2013), Boletín Microfinanciero Trimestral, № 40, Quito [en línea] http://www.rfr.org. SBS (Superintendencia de Bancos y Seguros) (2013), Boletín de Series Bancos Privados [en línea] http:// www.sbs.gob.ec.

Schicks, J. (2013a), "The definition and causes of microfinance over-indebtedness: a customer protection point of view", Oxford Development Studies, vol. 41, sup. 1, Taylor \& Francis.

- (2013b), "The sacrifices of micro-borrowers in Ghana - A customer-protection perspective on measuring over-indebtedness", Journal of Development Studies, vol. 49, № 9, Taylor \& Francis.

SEPS (Superintendencia de Economía Popular y Solidaria) (2014), Ley orgánica de la economía popular y solidaria y del Sistema Financiero Popular y Solidario de 28 de abril de 2011, Quito.

_ (2013), Boletín Financiero - Sector Financiero Popular y Solidario al 30 de junio de 2013 [en línea] http:// www.seps.gob.ec.

Shorrocks, A., J. Davies y R. Lluberas (2012), Credit Suisse Global Wealth Report 2012, Zurich, Credit Suisse Research Institute [en línea] https://publications.credit-suisse.com/tasks/render/file/index. cfm?fileid=88EE6EC8-83E8-EB92-9D5F39D5F5CD01F4.

Vogelgesang, U. (2003), "Microfinance in times of crisis: the effects of competition, rising indebtedness and economic crisis on repayment behavior", World Development, vol. 31, № 12, Amsterdam, Elsevier. 